\title{
Hepatitis C Status in Karachi, Pakistan, a Five-Year Survey at Civil Hospital, Karachi, Pakistan
}

\author{
Ghulam Fatima1,2, Shehla Shaheen ${ }^{3}$, Anam Razzak², Suresh Kumar², M. Saeed Quraishy², \\ Shahana Urooj Kazmi ${ }^{1,4}$ \\ ${ }^{1}$ Immunology and Infectious Diseases Research Laboratory, University of Karachi, Karachi, Pakistan \\ ${ }^{2}$ Civil Hospital Karachi, Karachi, Pakistan \\ ${ }^{3}$ Department of Pharmacology, Ziauddin Medical College, Ziauddin University, Karachi, Pakistan \\ ${ }^{4}$ Department of Clinical Microbiology, Dada Bhoy Institute of Higher Education, Karachi, Pakistan \\ Email:drfatima63@gmail.com
}

Received 7 October 2015; accepted 7 November 2015; published 10 November 2015

Copyright (C) 2015 by authors and Scientific Research Publishing Inc.

This work is licensed under the Creative Commons Attribution International License (CC BY).

http://creativecommons.org/licenses/by/4.0/

(c) (i) Open Access

\section{Abstract}

Hepatitis C virus is associated with Hepatitis $\mathrm{C}$ which can be acute or chronic. Acute hepatitis $\mathrm{C}$ is usually short term illness that can lead to chronic infection, while chronic hepatitis $C$ is a chronic liver disease leading to cirrhosis, hepatocellular carcinoma and even death. The mode of transmission is mainly parenteral and vertical. Hepatitis $C$ is the leading cause of morbidity and mortality and a serious public health problem, worldwide as well as in Pakistan. There is no vaccine available for hepatitis $C$ so the only way to prevent hepatitis $C$ is by changing behaviors which can spread the disease. Pakistan is also facing a huge burden of this disease. In Pakistan, the frequency of hepatitis $C$ virus infection ranges from $8 \%-15 \%$ in the general population with variations in different parts of the country. The general method of detecting infection with $\mathrm{HCV}$ is to observe the presence of antibodies to the virus. The aim of this study was to determine frequency of hepatitis $C$ among general population and to see the increasing frequency in our part. Selection of Patients: All patients visiting outpatient clinics, Hepatitis clinic and indoor patients at Civil Hospital Karachi, Pakistan from January 1, 2010 to December 31, 2014 were screened for anti HCV. Methods: Blood samples were collected from the patients in Red Topped vaccutainers and allowed to clot, then centrifuged and serum was screened for anti HCV by Immunochromatography (ICT) method. Results: A total of 156,990 patients were screened for anti-HCV, 23,511 (14.98\%) patients were reported positive. During the year 2010, total 11,058 patients were screened for anti HCV, 1791 (16\%) were positive, while in the year 2011 total 26,921 were screened and $3908(14.5 \%)$ were positive, during the year 2012 , total 23,321 were screened, $3036(14 \%)$ were positive, in the year 2013 we screened total 40,483 patients $6070(15 \%)$ were positive, while in 2014 , total 55,484 patients were screened and 8584 were positive (15.5\%). The most affected age group is between 21 - 
40 years and males are affected more than females. Conclusion: Hepatitis $\mathrm{C}$ in increasing in our population affecting the young generation between the age of 21 - 40 years and male population is affected more than females so a mass screening is needed to know the exact position of the disease as well as awareness programs should be started using media.

\section{Keywords}

\section{HCV, Anti-HCV, Immunochromatography}

\section{Introduction}

Hepatitis is the inflammation of liver and if it is caused by viral infections it is called viral hepatitis. Most common viruses associated with viral hepatitis are five viruses, hepatitis A to E, while other viruses like herpes, cytomegalovirus etc. can also cause hepatitis. Hepatitis C was first cloned in 1989 [1] [2]. Hepatitis C virus (HCV) is an enveloped, positive-sense single-stranded RNA virus which belongs to the family Flaviviridae, and genus Hepacivirus, which contains small genome of about 9600 nucleotides. Due to genetic variability, there are 6 identified genotypes.

Hepatitis $\mathrm{C}$ is the leading cause of morbidity, mortality and a serious public health problem, worldwide including Pakistan [3]. Nearly 500 million people are estimated to be infected with hepatitis C worldwide [4]. The World Health Organization (WHO) had estimated that 180 million people are infected with hepatitis C virus in 2009. Three to four million people get newly infected with HCV every year [5]. Two thirds of these newly infected cases develop chronic liver diseases [5].

The global prevalence of HCV infection is $2.2 \%$ to $3 \%$ [6]. In the United States the prevalence of HCV is 1.6 to $1.8 \%$ and in the European countries, the prevalence is $1 \%$ to $2.3 \%$ [7].

Pakistan is the $6^{\text {th }}$ most populous country in the world with an estimated population of $160,943,000$. Prevalence of HCV infection reported in various studies by the Pakistani authors ranges from 2.2\% - 14\% [8]. About 10 million people are infected with HCV in Pakistan [9] [10]. Within Pakistan, the HCV prevalence rate varies between the four provinces; prevalence rate reported in Punjab is 6.7\%, in Sindh 5\%, in Baluchistan 1.5\%, and in Khyber Pakhtunkhwa 1.1\% [11]. Hepatitis C can be acute or chronic. Acute hepatitis C is usually a short term illness which may progress to chronic infection with symptomatic or asymptomatic carrier state which may lead to serious consequences like cirrhosis, hepatocellular carcinoma and even death [5].

The mode of transmission is mainly parenteral and vertical. Hepatitis $C$ is commonly transmitted by percutaneous exposure to contaminated blood and as little as $0.01 \mathrm{ml}$ can transmit infection making them a big culprit [12]. The transmission risk of these viruses increases among persons who are given therapeutic drugs using un-sterilized syringes [13], sharing of infected needles, among IV drug abusers [14], reuse of razors [15], having transfusion of contaminated blood, patients on haemodialysis [16], unsafe sex, dental procedure with infected instruments, endoscopies with un-sterilized instruments, the cosmetic alterations like body piercing or tattooing done by un-sterilized needles are becoming major threats for transmission of hepatitis viruses. The risk of transmission of HCV from viremic (HCV RNA positive) mothers to their infants is $3.2 \%$ and transmission risk further increases if the mother is coinfected with HIV to 7.9\% [17]. There is no vaccine available for hepatitis C so the only way to prevent hepatitis $\mathrm{C}$ is by changing behaviors which can spread the disease. Pakistan is also facing a huge burden of this disease, the frequency ranges from $8 \%-15 \%$ in the general population with variations in different parts of the country. The general method of detecting infection with HCV is to observe the presence of antibodies to the virus.

Various tests are available for the diagnosis of hepatitis $C$ which include anti HCV, HCV RNA, viral load, genotyping of HCV by PCR. But for screening purpose anti HCV is internationally recommended.

For the detection of anti-HCV in the serum, the different techniques available in the market are immunochromatography (ICT), enzyme linked immune sorbant assay (ELISA), chemiluminescence microparticle immunoassay (CMIA) and polymerase chain reaction (PCR). The rapid immunochromatography (ICT) anti-HCV test is a simple, visual qualitative test that detects antibodies in human serum or plasma and can give results within 15 minutes. Immunochromatography can be used for screening as it is rapid and reliable technique as we carried out a study in 2011 to compare different techniques of anti HCV. All the positive tests must be confirmed by 
other superior techniques.

\section{Background}

The aim of this study was

1) To determine the frequency of hepatitis $C$ among general population.

2) To see the increasing frequency in our part, as the data for the prevalence of hepatitis $C$ virus (HCV) infections among general public in Karachi is currently unavailable accurately.

3) To determine and compare the increasing trend of hepatitis $C$ in the last five years (2010-2014).

4) To compare the Demographic characteristics of patients with hepatitis $C$ infection.

\section{Materials and Methods}

Study Period: January 1, 2010 to December 31, 2014.

Selection of Patients: All patients visiting outpatient clinics of medical, surgical and allied units, Gynae \& Obs. Pediatrics, hepatitis clinic and indoor patients at Civil Hospital Karachi, Pakistan who were either showing symptoms of hepatitis or undergoing any surgical procedure/instrumentation, antenatal patients, from January 1 , 2010 to December 31, 2014 were screened for anti-HCV.

Methods: Blood samples were collected aseptically from the patients in Red Topped vacutainers and allowed to clot, then centrifuged and serum was screened for anti-HCV by Imunochromatography (ICT) method. Positive samples were confirmed by Enzyme Linked Immuno Assay (ELISA), Chemiluminescence Microparticle Immunoassay (CMIA).

\section{Results}

A total of 156,990 patients were screened for hepatitis C Virus specific antibodies by Immunochromatographic (ICT) technique, over a period of five years from January 2010 to December 2014, out of which 23,511 (14.98\%) patients were reported positive (Figure 1). Percentage distribution during this period is shown in Figure 2.

During the year 2010, a total of 10,826 patients were Screened for anti HCV by Immunochromatographic (ICT) technique, 1913 (17.6\%) patients were found to be positive, in 2011 total 26,921 were screened and 3908 (14.5\%) were positive, in 2012, total 23,321 were screened 3036 (14\%) were reactive and in 2013, out of 40,483 patients, 6070 (15\%) were reactive, while in 2014, total 55,484 patients were screened and 8584 were positive (15.5\%) (Figure 1 \& Figure 2).

The most affected age group is between 21 - 40 years (Table 1, Figure 3).

Males are affected more than females (Figure 4).

History of injection was found in $75 \%$ patients (Table 2).

\section{Year wise HCV cases 2010-2014}

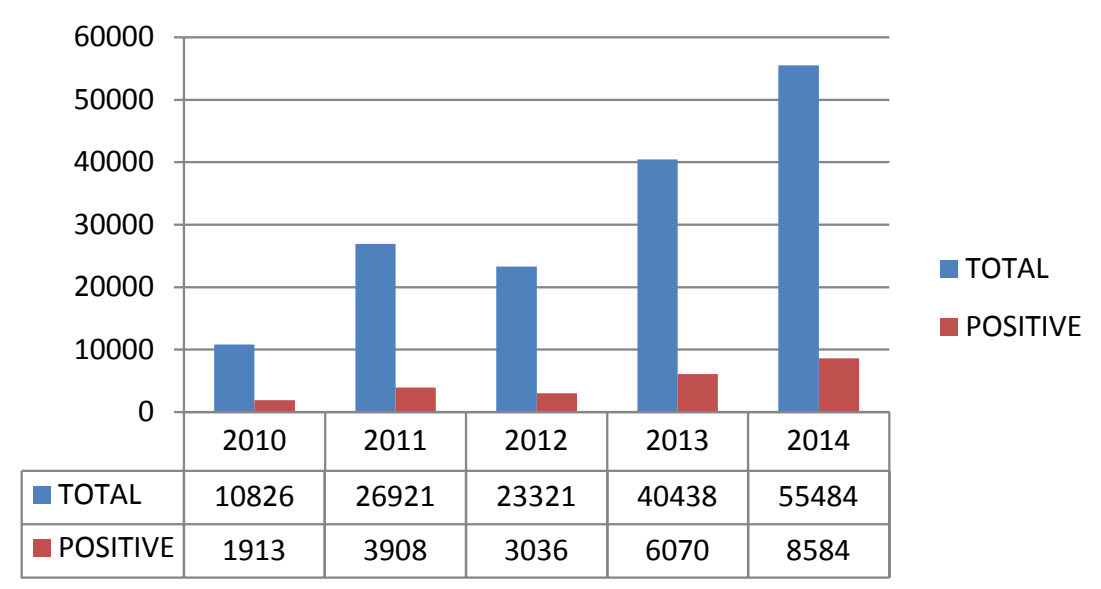

Figure 1. HCV positive cases during 2010-2014. 


\section{Prevalence of HCV Specific antibodies 2010-2014}

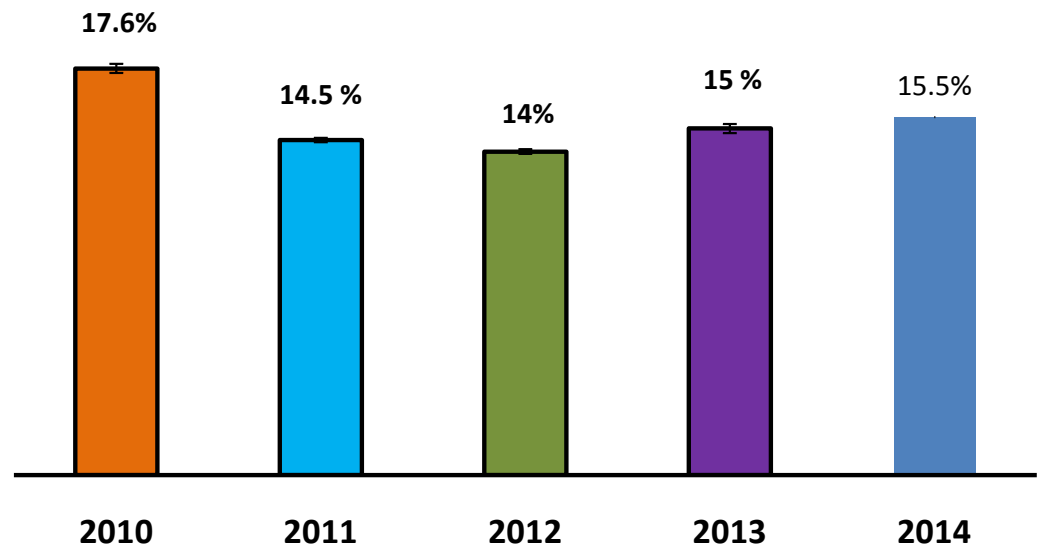

Figure 2. Percentage Prevalence of HCV cases from 2010-2014.

\section{Age wise Distribution of HCV 2010-2014}

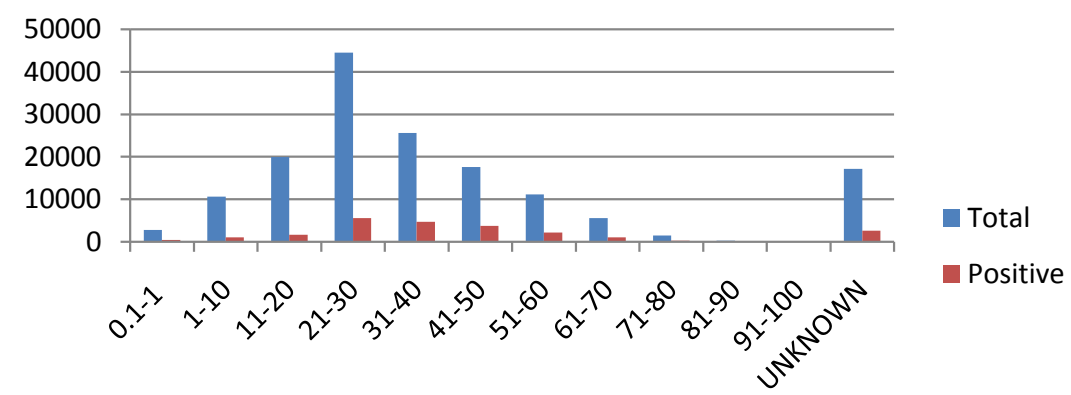

Age in Years

Figure 3. Age distribution of HCV in Karachi, Pakistan 2010-2014.

\section{Gender wise Distribution of HCV} 2010-2014

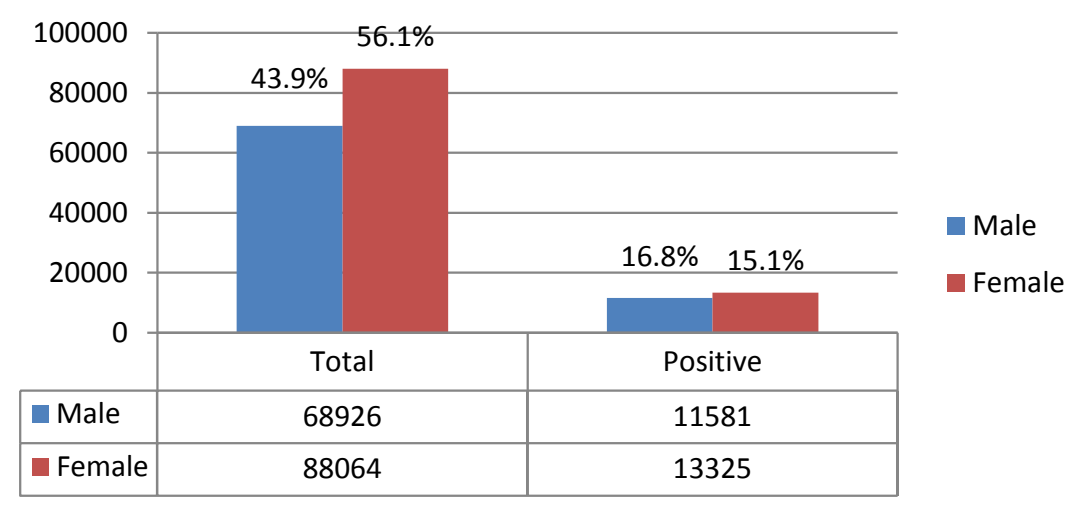

Figure 4. Sex distribution of HCV cases. 
Table 1. Age wise distribution of HCV specific antibody positive patients.

\begin{tabular}{|c|c|c|c|c|c|c|c|c|c|c|}
\hline \multirow{3}{*}{$\begin{array}{l}\text { AGE IN } \\
\text { YEARS }\end{array}$} & \multicolumn{10}{|c|}{ YEARS } \\
\hline & \multicolumn{2}{|c|}{2010} & \multicolumn{2}{|c|}{2011} & \multicolumn{2}{|c|}{2012} & \multicolumn{2}{|c|}{2013} & \multicolumn{2}{|c|}{2014} \\
\hline & TOTAL & POSITIVE & TOTAL & POSITIVE & TOTAL & POSITIVE & TOTAL & POSITIVE & TOTAL & POSITIVE \\
\hline $0.1-1$ & 51 & 2 & 107 & 18 & 94 & 16 & 1969 & 298 & 607 & 70 \\
\hline $1-10$ & 496 & 46 & 1270 & 87 & 1203 & 49 & 2603 & 223 & 5074 & 676 \\
\hline $11-20$ & 997 & 120 & 2896 & 230 & 2832 & 173 & 5569 & 447 & 7573 & 684 \\
\hline $21-30$ & 2138 & 334 & 7268 & 897 & 6323 & 723 & 12,311 & 1557 & 16,398 & 2113 \\
\hline $31-40$ & 1510 & 293 & 3640 & 605 & 3299 & 592 & 6940 & 1329 & 9398 & 1850 \\
\hline $41-50$ & 1207 & 269 & 2642 & 538 & 2283 & 440 & 4906 & 1063 & 6584 & 1446 \\
\hline $51-60$ & 907 & 201 & 1866 & 378 & 1380 & 241 & 3032 & 616 & 3962 & 779 \\
\hline $61-70$ & 448 & 95 & 970 & 199 & 674 & 110 & 1603 & 285 & 1898 & 330 \\
\hline $71-80$ & 94 & 22 & 259 & 53 & 164 & 29 & 413 & 75 & 564 & 86 \\
\hline $81-90$ & 21 & 4 & 56 & 9 & 29 & 3 & 100 & 21 & 117 & 18 \\
\hline $91-100$ & 3 & 0 & 6 & 0 & 5 & 0 & 9 & 2 & 16 & 6 \\
\hline UNKNOWN & 2954 & 527 & 5941 & 896 & 5035 & 660 & 0 & 0 & 3293 & 526 \\
\hline
\end{tabular}

Table 2. Possible risk factors for HCV disease transmission in Pakistan [20].

\begin{tabular}{cc}
\hline Risk Factors & HCV POSITIVE \% \\
\hline Use of Injection & 3.7 \\
None & 4.5 \\
$<5 /$ Year & 6.1 \\
$5-10 /$ Year & 8.3 \\
$>10 /$ Year & \\
Type of Syringe & 3.5 \\
New Disposable Syringes & 6.8 \\
Used Syringes & \\
Shaving & 7.5 \\
Home & 9.8 \\
Barber & 8.4 \\
Sharing Tooth Brushes/Miswak & 11.5 \\
Sharing Cigarettes/Hukahs/Biddi & 8.3 \\
Tattooing/Acupuncture & 5.8 \\
Nose/Ear Piercing & 9.8 \\
History of Hospitalization & 10.1 \\
History of Surgery & \\
\hline
\end{tabular}

\section{Discussion}

Hepatitis $C$ is endemic in most parts of the world in developing countries including Pakistan. In our local literature, the antibodies to hepatitis $C$ virus were found to be 20 folds higher than in developed countries [18]. Many studies were conducted in Pakistan during the past decade and guidelines for the prevention and control of hepatitis were formulated. Even then the graph of hepatitis $C$ positive patients is going up in our population because 
of unawareness about disease and its mode of spread. The overall incidence in general Pakistani population ranges between $4 \%-25 \%$ [19] which is alarming.

Pakistan has been rated amongst the countries with high risk of HCV infections. A very high prevalence of hepatitis C (14\% - 16\%) found in this study suggested that an alarming situation exist as compared to earlier report of (4.9\%) in general population of Pakistan [20], in which it was found that 12 million people of Pakistan are affected by one of the hepatitis viruses. In our study, the prevalence rate was higher due to the segment of population who were sick/unhealthy while other studies were carried out on healthy population.

A study conducted at Karachi by Shirazi and colleagues showed prevalence of hepatitis C 9.24\% with overall prevalence of hepatitis viruses 18\% [21], in elective surgical patients. Another study conducted at Karachi by Zubia and her colleagues showed prevalence of hepatitis C 11.3\% [22]. A study conducted by Chaudhary and his colleagues at Rawalpindi, showed the prevalence of hepatitis C $11.26 \%$, in elective surgical patients [23].

In our study, males were affected slightly more than females, even more female patients included in our study as the patients from Gynecology, Obstetrics wards and Antenatal Clinics were also included.

The most affected age group was between 21 - 40 years, because this age group is the most active age group passing reproductive phase of life which is again alarming because the future of Country lies on this population. This age group is at risk as this is young group who forms the productive work force of the country.

The studies have also been conducted on hepatitis B and C in pregnant women. Zafar et al. [24] conducted a study at a hospital in Lahore on 300 pregnant women and showed anti-HCV prevalence to be $6 \%$ while another study at Islamabad revealed anti-HCV prevalence to be 3.7\% [25]. Another study conducted at Lahore on pregnant women, reported anti-HCV positivity to be $7.3 \%$.

In a study by Bhopal FG et al. [26] out of 300 surgical patients $6.33 \%$ for anti-HCV, A study by Haroon Khan et al. [27] which enrolled 695 patients reported 4.5\% patients were Anti HCV positive. Results from another study [28] showed $8.66 \%$ for HCV antibody positive patients respectively. All of these are lower as compared to our study.

A more recent study of 142 patients screened before surgery showed that $11.26 \%$ were positive for anti-HCV [26]. In a study carried in Jacobabad Sindh, 14\% HCV positive reported in preoperative patients [29]. This also compares well with our findings of $14 \%-16 \%$ of patients found to be HCV positive.

In a very large study of United States conducted during 1988 through 1994 reported overall prevalence of HCV $1.8 \%[30]$.

In an epidemiological study of 34,336 patients from Japan the prevalence of HCV seropositivity was 7.1\% [31]. A study from Turkey reported the prevalence of anti-HCV was $2.4 \%$ as compared to $14 \%-16 \%$ in our study which is significantly higher [32]. The results of international studies are not comparable to our local results especially in case of HCV, reason being more awareness and better preventive measures, in developed countries.

The commonest mode of HCV transmission, as mentioned in literature is by the contaminated blood and its products, use of un-sterile syringes, sharp surgical instruments and needles. Doctors and health care professionals are at high risk of acquiring the disease. In operation theatre accidental cuts and pricks to the surgeons or their assistants and spillage of blood drops in to eyes are commonest modes of transmission to them and at the same time operation theatre may act as the source of spread of the disease to other patients if proper precautions are not taken.

Contaminated needles and equipments can transmit infection even after months being soiled by virus [33]. An average risk of HCV transmission after needle stick injury is estimated to be about 1.8\% [28]. In our study history of frequent use of I/V and I/M injections was present in 95.4\% HCV reactive patients which is comparable to the report of PMRC [19] followed by history of instrumentation. In a study from USA parenteral drug use was reported to be the major risk factor in majority of HCV positive cases [29].

Efforts are needed to raise awareness about HCV infections from being an almost forgotten to a well attended one. Moreover, in view of the high infection rate, all preventive measures should be adopted to check and control these viral diseases. Since majority of carriers are asymptomatic, they pose a real threat to health staff through self pricks and other patients who share the same surgical instruments. The prevalence of HCV in hospitalized surgical patients is very high and there is lack of routine serological screening prior to surgery which is one of the factors responsible for increased viral transmission. Surgeons, theatre staff, nurses and other healthcare workers are at greater risk of acquiring these infections.

The possibility of vertical transmission highlights the importance of mandatory ante partum screening for 
HCV. Patients undergoing any surgical procedure may have these infections, demanding special precautions.

\section{References}

[1] Choo, Q.L., Kuo, G., Weiner, A.J., Overby, L.R., Bradley, D.W. and Houghton, M. (1989) Isolation of cDNA Clone Derived from a Blood-Borne Non-A, Non-B Viral Hepatitis Genome. Science, 21, 359-362. http://dx.doi.org/10.1126/science.2523562

[2] Kuo, G., et al. (1989) An Assay for Circulating Antibodies to a Major Etiologic Virus of Human Non-A, Non-B Hepatitis. Science, 21, 362-364. http://dx.doi.org/10.1126/science.2496467

[3] Shah, H.N. and Shabbir, G. (2002) A Review of Published Literature on Hepatitis B \& C Virus Prevalence in Pakistan. Journal of the College of Physicians and Surgeons Pakistan, 12, 368-371.

[4] Tanwani, K. and Ahmad, N. (2000) Prevalence of Hepatitis B Surface Antigen and Anti-Hepatitis C Virus in Laboratory Based Data at Islamabad. Journal of Surgery, 19, 25-29.

[5] Perz, J.F., Armstrong, G.L., Farrington, L.A., Hutin, Y.J. and Bell, B.P. (2006) The Contributions of Hepatitis B Virus and Hepatitis C Virus Infections to Cirrhosis and Primary Liver Cancer Worldwide. Journal of Hepatology, 45, 529538. http://dx.doi.org/10.1016/j.jhep.2006.05.013

[6] Lavanchy, D. (2009) The Global Burden of Hepatitis C. Liver International, 29, 74-81. http://dx.doi.org/10.1111/j.1478-3231.2008.01934.x

[7] Marcellin, P. (2009) Hepatitis B and C in 2009. Liver International, 29, 1-8. http://dx.doi.org/10.1111/j.1478-3231.2008.01947.x

[8] Sy, T. and Jamal, M.M. (2006) Epidemiology of Hepatitis C Virus (HCV) Infection. International Journal of Medical Sciences, 3, 41-46. http://dx.doi.org/10.7150/ijms.3.41

[9] Raja, N.S. and Janjua, K.A. (2008) Epedemiology of Hepatitis C Virus Infection in Pakistan. Journal of Microbiology, Immunology and Infection, 41, 4-8.

[10] Umar, M., Bushra, H., Ahmad, M., Khurram, M., Usman, S., Arif, M., Adam, T., Minhas, Z., Arif, A., Naeem, A., Ejaz, K., Butt, Z. and Bilal, M. (2010) Hepatitis C in Pakistan: A Review of Available Data. Hepatitis Monthly, 10, $205-214$.

[11] Umar, M. and Bilal, M. (2002) Hepatitis C, A Mega Menace: A Pakistani Perspective. Journal of Pakistan Medical Students, 2, 68-72.

[12] Walter, J.B. and Isreal, M.S. (1987) Viral Infections of Human Beings. 6th Edition, General Pathology, Churchill Livingston, $310 \mathrm{p}$.

[13] Shaikh, M.A., Shaikh, W.M., Solangi, G.A. and Abro, H. (2003) Frequency and Transmission Mode of Hepatitis C Virus in Northern Sindh. Journal of the College of Physicians and Surgeons Pakistan, 13, 691-693.

[14] Hauri, A.M., Armstrong, G.L. and Hutin, Y.J. (2004) The Global Burden of Disease Attributable to Contaminated Injections Given in Health Care Settings. International Journal of STD \& AIDS, 15, 7-16. http://dx.doi.org/10.1258/095646204322637182

[15] Janjua, N.Z. and Nizamy, M.A. (2004) Knowledge and Practices of Barbers about Hepatitis B\&C Transmission in Rawalpindi and Islamabad. Journal of Pakistan Medical Association, 54, 116-119.

[16] Shafi, T. and Iqbal, A.S. (1992) Prevalence of Anti Hepatitis C in Haemodialysis Patients. Pakistan Journal of Medical Research, 31, 42-45.

[17] Davis, G.L. (2007) Hepatitis C. In: Schiff's Diseases of the Liver, 10th Edition, Lippincott Williams and Wilkins, Philadelphia, 807-863.

[18] Aziz, S., Memon, A., Tily, H.I., Rasheed, K., Jehangir, K. and Quraishy, M.S. (2003) Prevalence of HIV, Hepatitis B\&C amongst Health Workers of Civil Hospital Karachi. Journal of Pakistan Medical Association, 53, 136-140.

[19] Batool, A., Bano, K.A., Khan, M.I. and Hussain, R. (2008) Antenatal Screening of Women for Hepatitis B and C in an Out-Patient Department. Journal of the Dow University of Health Sciences, 2, 32-35.

[20] Qureshi, H., Bile, K.M., Jooma, R., Alam, S.E. and Afridi, H.U.R. (2010) Prevalence of Hepatitis B and C Viral Infections in Pakistan: Findings of a National Survey Appealing for Effective Prevention and Control Measures. Eastern Mediterranean Health Journal, 6, S15-S23.

[21] Shirazi, B., Jeffery, A.H., Kishwar, M. and Shahid Shamim, M. (2004) Screening for Hepatitis B\&C in Surgical Patients. Journal of Surgery Pakistan, 9, 10-13.

[22] Masood, Z., Jawaid, M., Khan, R.A. and Rehman, S. (2005) Screening for Hepatitis B \& C: A Routine Preoperative Investigation? Pakistan Journal of Medical Sciences, 21, 455-459.

[23] Chaudhary, I.A. and Khan, S.A. (2005) Samiullah. Should We Do Hepatitis B and C Screening on Each Patient before Surgery. Pakistan Journal of Medical Sciences, 21, 278-280. 
[24] Zafar, M.A., Mohsin, A., Hussain, I. and Shah, A.A. (2001) Prevalence of Hepatitis C among Pregnant Women. Journal of Surgery Pakistan, 6, 32-33.

[25] Jaffery, T., Tariq, N., Ayub, R. and Yawar, A. (2005) Frequency of Hepatitis C and Pregnancy Outcome. Journal of the College of Physicians and Surgeons Pakistan, 15, 716-719.

[26] Bhopal, F.G., Yousaf, A. and Taj, M.N. (1999) Frequency of Hepatitis B and C: Surgical Patients in Rawalpindi General Hospital. Professional Medical Journal, 6, 502-509.

[27] Khan, H., Khan, N., Niazi, R., Adam, T. and Yaqoob, A. (2001) Seroprevalence of Hepatitis C in Pakistanis Visiting and Admitted at the Pakistan Institute of Medical Sciences Islamabad. Journal of Surgery, 21, 22-26.

[28] Mengal, M.A., Abbas, F., Mengal, M.A., Shafee, M., Babar, S., Mengal, M.A. and Atique, A. (2012) Passive Surveillance of Anti-Hepatitis C Virus Antibodies in Human Subjects of Four Medical Units of Balochistan, Pakistan. International Journal of Agriculture and Biology, 14, 585-589.

[29] Daudpota, A.Q. and Soomro, A.W. (2008) Seroprevalence of Hepatitis B and C in Surgical Patients. Pakistan Journal of Medical Sciences, 24, 483-484.

[30] Satyanarayana, R. and Melman, M.L. (2001) Liver Diseases, Viral Hepatitis. 30th Edition, The Washington Manual of Medical Theraputics, Lippincott Williams and Wilkins, Philadelphia, 380-81.

[31] Taguchi, S., Nishioka, K., Kawaguchi, R., Nakao, M., Watanabe, I. and Migita, T. (2004) Epidemiological Study of Hepatitis B and C in 34,336 Patients Operated at Hiroshima Prefectural Hospital during the Period from 1993 to 2000. Masui, 53, 696-700.

[32] Erden, S., Buyukozturk, S., Calangu, S., Yilmaz, G., Palanduz, S. and Badur, S. (2003) Study of Serological Markers of Hepatitis B and C Viruses in Istanbul, Turkey. Medical Principles and Practice, 12, 184-188. http://dx.doi.org/10.1159/000070757

[33] Yousaf, A., Mahmmod, A. and Ishaq, M. (1996) Can We Afford to Operate on Patients without HBsAbg Screening? Journal of the College of Physicians and Surgeons Pakistan, 9, 98-100. 